Int. J. Electrochem. Sci., 14 (2019) $9876-9887$

\title{
Combined Machining of Ti-6Al-4V Alloy Using Electrochemical Milling and Electrochemical Grinding
}

\author{
Gangqiang Liu, Hansong Li*, Shen Niu, Xiaokang Yue and Ningsong $Q u$
}

National Key Laboratory of Science and Technology on Helicopter Transmission, Nanjing, China, 210016

*E-mail: $\underline{\text { hsli@ nuaa.edu.cn }}$

doi: $10.20964 / 2019.10 .39$

Received: 28 March 2019 / Accepted: 16 July 2019 / Published: 30 August 2019

Ti-6Al-4V is a typical difficult-to-cut material with which it is difficult to achieve a high processing efficiency and good surface quality simultaneously using a single processing method. In this paper, a combined method that consists of electrochemical milling and grinding is proposed to solve this problem. Two types of electrodes were used in the different machining stages. First, the polarization curves for Ti-6Al-4V in $10 \% \mathrm{NaNO}_{3}$ solution were obtained. Then, the maximum feed and material removal rates were studied using various electrochemical milling parameters. The resulting machined groove crosssectional profiles were compared. Finally, the effects of electrochemical grinding on the machining results were investigated. The machined workpiece surfaces were examined using scanning electron microscopy and their roughnesses were measured using a roughometer.

Keywords: Ti-6Al-4V alloy; Electrochemical milling; Electrochemical grinding; material removal rate; surface roughness

\section{FULL TEXT}

(C) 2019 The Authors. Published by ESG (www.electrochemsci.org). This article is an open access article distributed under the terms and conditions of the Creative Commons Attribution license (http://creativecommons.org/licenses/by/4.0/). 